\title{
The effect of early retirement schemes on youth employment
}

\section{Keeping older workers in the workforce longer not only doesn't harm the employment of younger workers, but might actually help both}

Keywords: early retirement, youth unemployment, social policy

\section{ELEVATOR PITCH}

The fiscal sustainability of state pensions is a central concern of policymakers in nearly every advanced economy. Policymakers have attempted to ensure the sustainability of these programs in recent decades by raising retirement ages. However, there are concerns that keeping older workers in the workforce for longer might have negative consequences for younger workers. Since youth unemployment is a pressing problem throughout advanced and developing countries, it is important to consider the impact of these policies on the employment prospects of the young.

\section{KEY FINDINGS}

\section{Pros}

( There is no trade-off in the employment of young and old workers: higher employment for older workers coincides with higher employment for younger workers.

$\oplus$ Increasing the retirement age increases younger workers' wages.

- Younger and older workers are complements for each other rather than substitutes.

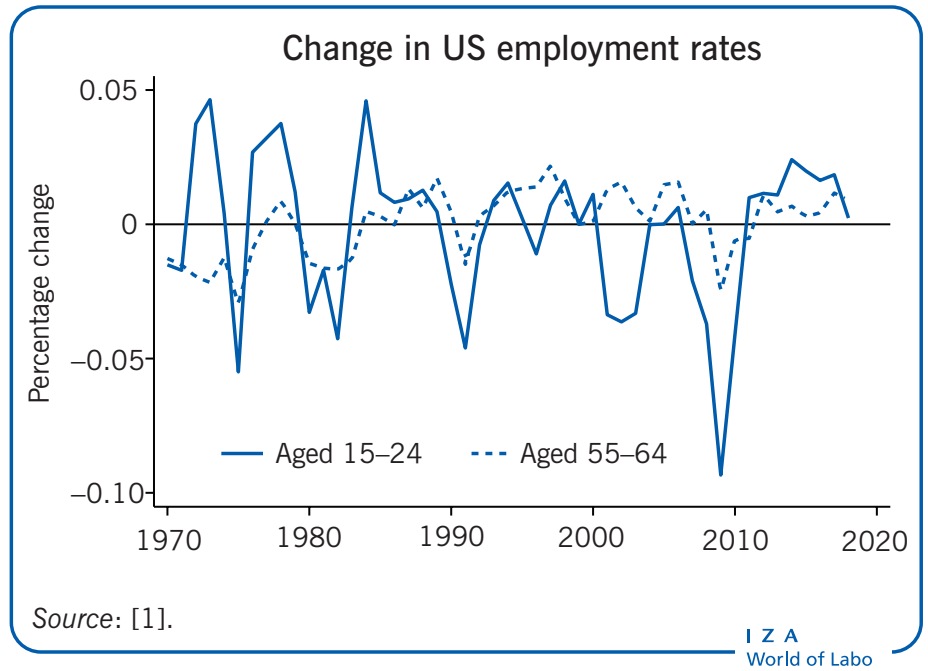

\section{Cons}

- Reducing the employment of older persons does not provide more job opportunities for younger persons.

- Increasing the employment of older persons neither reduces the employment, nor does it lead to more unemployment, of younger persons.

- Lowering the retirement age decreases the incentives to train and to invest in additional skills, and therefore leads to lower economic growth.

\section{AUTHOR'S MAIN MESSAGE}

Most OECD countries have reformed their pension systems by increasing the effective retirement age. It is often argued that a higher effective retirement age, which is considered necessary to sustainably finance state pensions, will lead to more youth unemployment. There is, however, no empirical evidence for this claim. On the contrary, increasing effective retirement ages and policies to foster employment of older workers are likely to support the employment of both older and younger workers. Policymakers, therefore, need not fear that such pension reforms will create problems for younger workers since, in all likelihood, increasing labor demand for one cohort will lead to more overall employment. 


\section{MOTIVATION}

Youth unemployment is a pressing problem throughout advanced and developing countries. According to the World Bank, the unemployment rate for persons aged 1524 ranged in 2018 from $0.4 \%$ in Niger to $44.6 \%$ in South Africa. However, of the 65 countries for which data are available, 59 had a male youth unemployment rate above 10\%. Data from the OECD for 2018 show that almost $6.3 \%$ of youth aged 15-19 were not in education, employment or training, with recent increases in the Baltic countries. Policymakers who advocate increases in the retirement age are accused of worsening the chances of young people getting jobs. Have recent increases in the retirement age for older workers worsened the employment prospects for today's youth?

\section{DISCUSSION OF PROS AND CONS}

During the 1990s, many OECD countries reformed their public pension systems. These efforts often reversed trends toward earlier retirement and led to an increase in average effective retirement ages in many countries. Due to transitory provisions which, for example, increase the retirement age gradually for different birth cohorts, the effective retirement age has not yet increased appreciably in these countries. However, for many OECD countries, it is already possible to observe a (modest) increase in the effective retirement age (one that will increase even more once the transitory provisions are phased out). As a result, older workers are likely to remain in the labor force longer than in earlier decades.

\section{Effective retirement age}

The average effective retirement age is the mean age at which older workers withdraw from the labor force to retire. In most countries, it is lower than the official retirement age. For example, in 2016, the official retirement age for men in Germany was 65 and the effective retirement age was 63 , according to the OECD. In most wealthy countries, the trend toward a lower effective retirement age dating back to the 1970s has been halted if not reversed. However, retirement ages are still generally below the levels of the 1970s. Life expectancy is rising faster than increases in the effective retirement age, which implies a longer time in retirement, raising concerns about old-age poverty and the sustainability of public pensions.

Those who oppose increasing the retirement age often argue that higher effective retirement ages will inevitably lead to lower employment among the young. For example, "one of the most popular arguments promulgated by the protesters [against the gradual increase of France's retirement age from 60 to 62 between 2010 and 2018], including those from the trade unions, students' and pupils' organizations, among others, was that increasing the retirement age by two years would decrease the chances of young people getting their first job" [2]. In addition, changing the retirement age is often interpreted as a form of active labor market intervention. According to an ILO report in 1999, "the basic public policy dilemma is the conflict between the use of early retirement as an instrument for alleviating unemployment among younger 
workers and the longer term financial viability of pension systems in ageing societies." Figure 1 details the development of the employment rates for 15- to 24-year-olds (as a percentage of total population) from 1990 to 2010. (The range differs due to the availability of comparable data.) The graphs show that youth employment rates declined over these years in most countries. In particular, during the financial crisis, the employment rate for youth declined substantially in most countries. The change is especially dramatic in Greece, Ireland, and Spain, as well as in Hungary and Portugal.

Figure 1. Employment rates of younger workers (15-24), 2000-2018

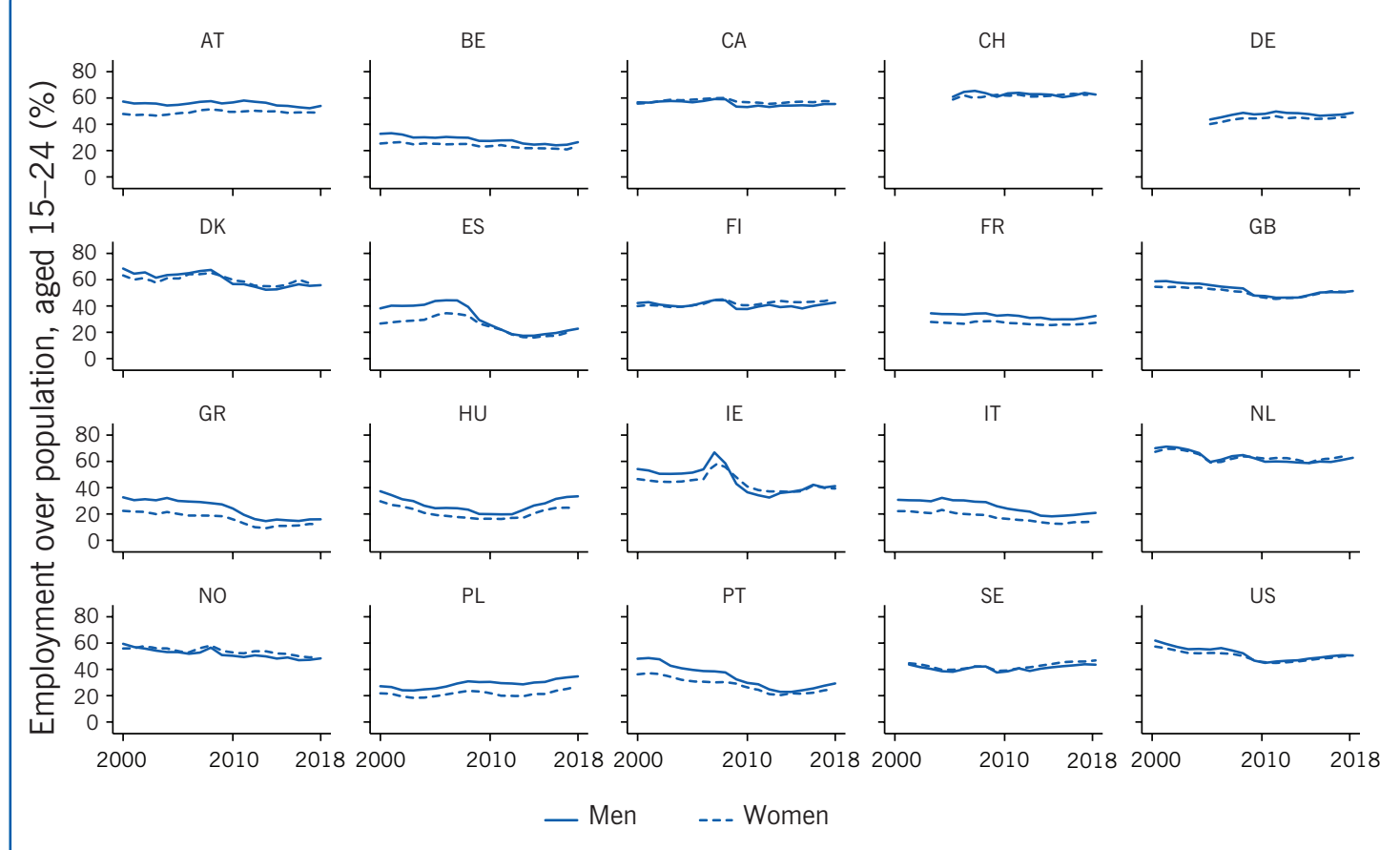

Source: OECD. "Main economic indicators—Complete database." Online at: http://dx.doi.org/10.1787/data-00052-en [Accessed October 5, 2019] [1].

Figure 2 presents the employment rates of men and women aged 55-64 for the years 1990-2010. Comparing the employment rates of younger and older workers presented in these two figures, it is not generally the case that the employment rates of younger workers declined in countries where the employment rates of older workers increased. Only in Hungary, Ireland, Norway, and Spain did the employment rates for older workers trend upward while the employment rates for younger workers declined-a correlation that was especially pronounced during the economic crisis of the late 2000s. In Finland, there was a definite increase in the employment of older workers, but little corresponding change in the employment of younger workers. By contrast, in Germany the employment rates of both younger and older workers increased.

Figure 3 shows the development of the effective retirement age for select OECD countries over the last few decades. In the 1970s, many OECD countries made it possible to retire earlier than the mandated retirement age, typically permitting workers who had accumulated a minimum number of contribution years to retire early. (In general, early 
Figure 2. Employment rates of older workers (55-64), 2000-2018

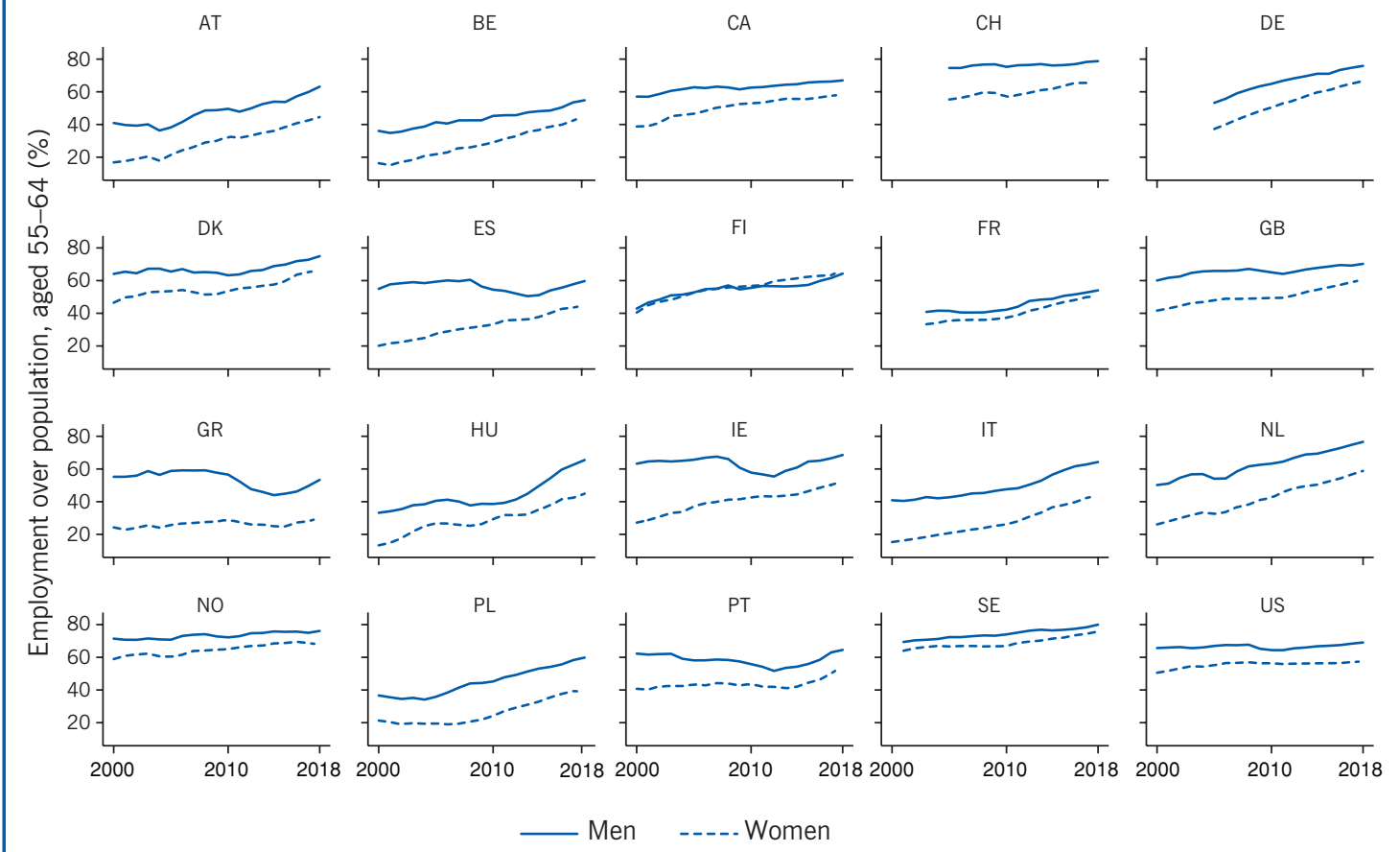

Source: OECD. "Main economic indicators—Complete database." Online at: http://dx.doi.org/10.1787/data-00052-en [Accessed October 5, 2019] [1].

Figure 3. Average effective retirement ages,2000-2018

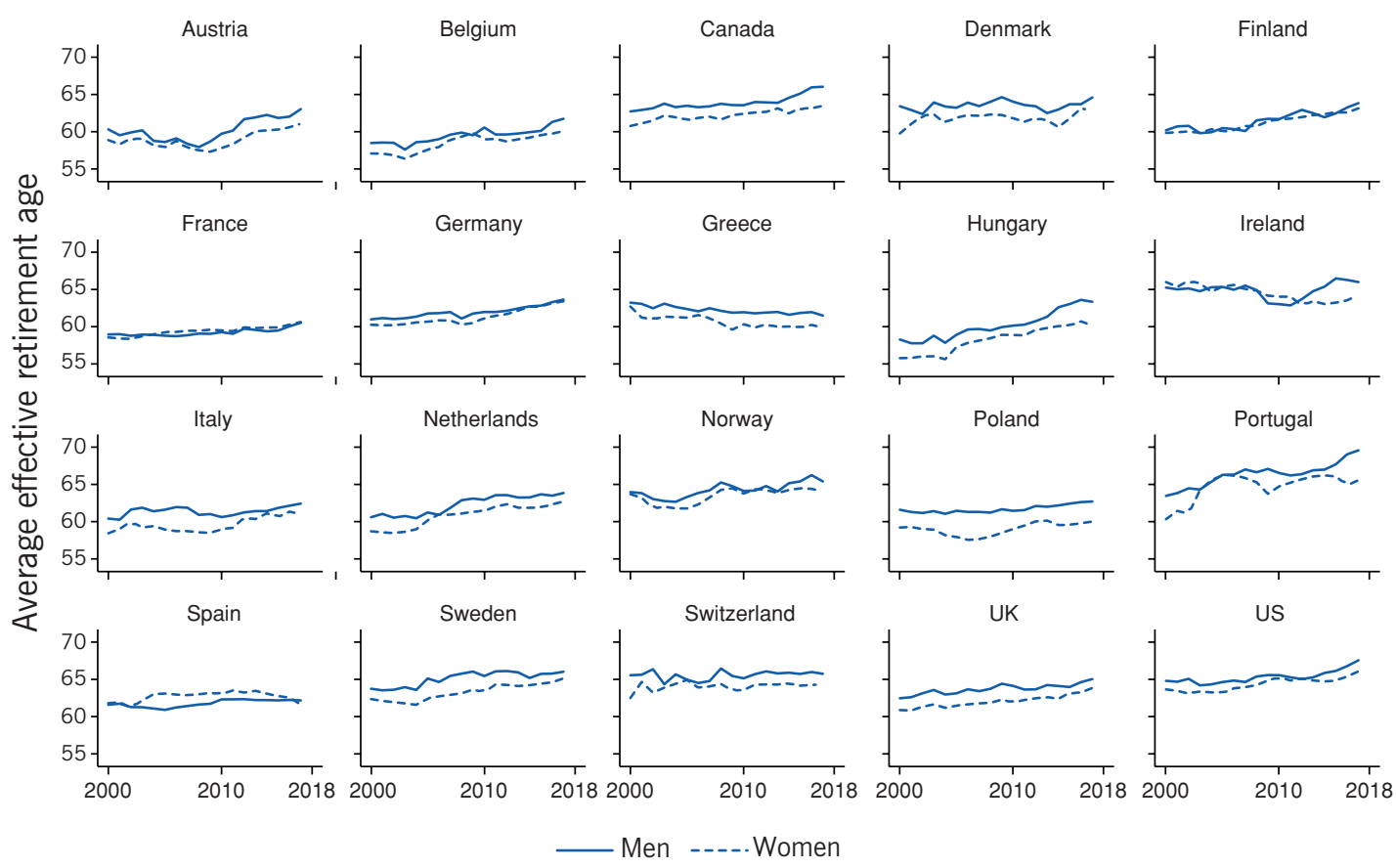

Source: OECD. "Statistics on age of retirement." Online at:http://www.oecd.org/els/emp/average-effective-age-ofretirement.htm [Accessed October 5, 2019]. 
retirement before that age had been available for disability or severe illnesses only.) Over that and the next decades, the effective retirement age declined and, together with increased longevity, public pensions formed an increasing burden on public budgets.

The argument that the early retirement of aging workers will lead to an increase of employment opportunities for young people rests, however, on two assumptions that lack empirical foundations. The argument requires first that overall employment in an economy is fixed, and second that young and old workers are easily substituted for each other.

\section{There is no upper limit of jobs in an economy}

The assumption that there is an upper limit on the number of jobs in an economy-the "lumpof-labor fallacy"-has no theoretical justification; nor is there empirical evidence to support such a view. In fact, as economies become more complex and grow due to specialization, additional jobs are being created. Technological progress, while rendering some occupations obsolete, constantly creates demand for new occupations. Research shows that having older people active and productive actually benefits all age groups and spurs the creation of more jobs. A 2012 analysis of Current Population Survey data tested for changes in employment among US workers under the age of 55 when those aged 55 and older worked in greater numbers [3]. The study found no evidence that younger workers lost work; in fact, it found the opposite: greater employment, reduced unemployment, and higher wages.

Another example of this effect is seen in the expansion of the employment of women during the second half of the 20th century in OECD countries: women did not replace men in the workforce; on the contrary, the transition to two-earner families increased disposable income, created new demand, and prompted firms to hire more workers. (It could be argued that in the very short term the number of jobs was fixed, because it takes time for this virtuous cycle to operate. However, it is known from a vast literature that there is an impressive amount of simultaneous job creation and job destruction, which stresses that even in the very short term the number of jobs is not limited.)

\section{Are young workers substitutes for older workers?}

If firms faced higher labor costs following an increase in the retirement age (e.g. because seniority decreases the profitability of older workers), they could substitute younger workers for older workers. Economic theory suggests that any substitution of one type of worker with another is governed by the similarity of the skills they possess. Empirical evidence, however, suggests that even workers of similar skills who differ by as little as five years in age are already imperfect substitutes, suggesting that firms would have, at most, a limited ability to substitute young workers for older ones [4]. As a consequence, the hiring behavior of firms in response to the cost of older workers indicates that substitution between young and old workers is limited. Even when the cost of employing older workers is significantly increased, the substitution of older with younger workers is moderate in scope [5].

Skill-based technical change might further decrease the substitutability between workers of different age cohorts. Technical change constantly adjusts the demand for skills. Although many jobs can now be more cheaply undertaken by computers, the demand for higher levels of skills (e.g. software engineers) has increased. However, learning new skills 
is costly and older workers may not invest in acquiring new skills if their remaining working life is too short to recoup the costs. In contrast, younger workers will more readily learn new skills because the period over which they can recover their costs is longer. Studies of US data indicate that the sector-specific rate of technological progress leads to more unemployment and the early retirement of older workers [6]. With older workers more likely to exit the labor market under these circumstances, rapid technological change makes the possibility of substituting younger workers for older ones even less likely.

The substitutability of younger and older workers might also depend on institutions such as the retirement system. In general, social systems can be characterized by their differences with respect to equity (i.e. regulations intended to lower economic and social inequality) and efficiency (i.e. regulations intended to optimize employment rates) [7]. The literature commonly uses a classification based on employment rates and poverty rates and describes countries as belonging to the "Nordic" model (high employment, low inequality), the "Anglo-Saxon" model (high employment, high inequality), the "Continental European" model (low employment, low inequality), and the "Mediterranean" model (low employment, high inequality). Because social models differ in their focus on employment and inequality, it is reasonable to expect to find a lower rate of substitutability between young and old workers in countries classified as Nordic than in, for instance, AngloSaxon countries. Empirical evidence does not indicate that different social models lead to greatly different rates of substitution between younger and older workers. An analysis of data for 22 OECD countries finds rather that workers of different age cohorts are complements, regardless of the dominant social model [8].

A detailed analysis of US data for 1977-2011 establishes a positive association between the employment rates of younger and older workers [8]. Furthermore, the analysis shows that not only are the employment rates positively correlated, but the wages of young workers are also positively correlated with higher employment for older workers. Recent evidence from Japan shows a negative effect of increasing the retirement age on the wages of older workers [9].

The positive correlations of employment rates and wages of young and old workers could be caused by a positive shock common to both age groups. However, careful econometric analysis indicates that this is not the case. Several robustness checks-for example, using different definitions of age groups and controlling for state population-confirm these findings. The most likely causes of the positive association of younger and older workers' employment and wages are the additional demand created by employed older workers and, in countries where pensions are financed by taxes, a reduction of the tax burden due to a lower number of inactive people. (There may also be additional benefits as moderate employment in older age has been found to be associated with better physical and mental health.)

Unfortunately, evidence of the substitutability of younger workers for older workers is limited for non-OECD countries. Data from China, published in 2012, however, suggest that the employment rates of young workers are positively associated with the employment rates of older workers [10].

\section{Later retirement ages increase employment of young workers}

Further empirical evidence on the substitutability of younger and older workers comes from studies that analyze "natural experiments"-that is, reforms that change the conditions for 
one group of workers but not for others [11]. These "quasi-experimental" situations allow the identification of causal effects from policy changes that could otherwise be biased. Evidence from Germany, where several reforms to the pension system have led to significant changes in the employment rate for older workers, provides strong support for the view that workers of different ages are complements rather than substitutes. Following one such reform in 1972, the employment rate for older workers dropped by seven percentage points by 1976. During the same period, the employment rate for younger workers declined by about two percentage points. In 1992, a pension reform changed the incentives for older workers to remain in employment longer, which led to a roughly 15 percentage point increase in the employment of older workers. At the same time, the youth unemployment rate declined slightly. Similar evidence can be observed following more recent reforms.

\section{Youth unemployment}

The youth unemployment rate is defined as the ratio of unemployed 15- to 24-yearolds to all 15- to 24-year-olds in the labor force (i.e. those who are employed or seeking employment). The definition of unemployment is, for reasons of comparability across countries, typically according to ILO conventions: a person is considered to be unemployed if she/he (i) did not work for even one hour in any economic activity (paid employment, self-employment, or unpaid work for a family business or farm); (ii) is currently available for work; and (iii) has actively taken steps to obtain work during a specified recent period (usually the past four weeks). In the OECD, South Africa (53\%), Greece (40\%), and Spain (34\%) had the highest youth unemployment rates in 2018; Japan (3.7\%) and Iceland (6\%) had the lowest. Across the OECD, the unemployment rate for youth, at about $11 \%$ in 2018 , is more than double the unemployment rate for the general population $(5.3 \%)$.

Moreover, Germany is not unique in this regard. Similar evidence is available for Denmark and France, where the employment of younger workers also tends to rise and fall together with the employment of older workers. Denmark introduced its Post-Employment Wage Program, an early retirement scheme, in 1979. This program led to a $35 \%$ decrease in the labor force participation rate for men aged 61-65. Before the reform, the unemployment rate of young workers had been relatively stable, while the employment rate was slightly increasing. After the reform, the employment rate of young workers dropped by about four percentage points.

In France, the employment rates of young workers dropped after pension system reforms that led to lower rates of labor market participation for older workers over the period 1971-1993. Subsequent reforms reversed this trend, leading to an increase in labor force participation for older workers between 1993 and 2005. This increase in the percentage of older workers in the labor force was accompanied by a corresponding increase in the employment rate of younger workers.

Cross-country comparisons, using panel data regressions, provide additional evidence. While these regressions permit the comparison of labor markets across countries, they typically do not exploit a quasi-experimental framework such as the analyses presented above. However, they do serve to establish whether the relationship between the employment of younger and older workers is significant or not, and whether this 
association is negative or positive. A positive association would be evidence against the trade-off between early retirement and the employment of young workers, and vice versa.

Empirical evidence from 12 countries-Belgium, Canada, Denmark, France, Germany, Italy, Japan, the Netherlands, Spain, Sweden, the UK, and the US-indicates that the employment rates of older and younger workers move together, rather than in opposite directions. The six countries with the greatest increases in the employment of older workers have seen the largest increases in youth employment. (They have also seen the greatest decreases in youth unemployment.) Different specifications and a series of robustness checks confirm these results.

Evidence from Italian firm-level data, however, suggests that when firms retain more older workers they hire fewer younger workers [12]. In Italy, the pension reform of 2011 is estimated to have reduced the employment of young workers by about $2.3 \%$. The size of a negative effect on youth employment may reflect the declining real GDP of the observation period and a longer time series does indeed result in a smaller, but still negative, effect. Rather than dramatically worsening young workers' job prospects, however, the greatest impact is instead on the layoffs of old and middle-aged workers, who are closer substitutes for those near retirement. Recent research using Norwegian data also finds that firms hire fewer younger workers when they retain older workers longer [13].

In summary, analyses of the impact of recent pension reforms in several countries on the effective retirement age of older workers and on the employment rate for younger workers typically arrive at the same conclusion: the employment rates of younger and older workers correlate positively. While some evidence exists that a higher pension age might cause an individual firm to postpone the hiring of younger workers, especially when employment protection for older workers is strong, the aggregate indicates no real evidence of a trade-off between jobs for younger and older workers. In addition, there is limited evidence that increasing the employment of older workers causes fewer jobs for younger workers, and vice versa.

\section{The impact of increased pension contributions}

While the early retirement of older workers does not lead to an increase in employment for younger workers, it does distort the returns for human capital accumulation and therefore leads to lower economic growth. Theoretically, early retirement shortens people's working life and reduces the incentive to accumulate human capital.

In addition, as life expectancies increase, early retirement may create a larger tax burden for future generations of workers. As contributions to the pension system are made over a shorter working life and consumed over a longer time spent in retirement, a lower retirement age may result in a lower level of benefit payments (assuming no increase in contributions from current workers). In order to maintain the level of retirement benefits, workers may be forced to make higher contributions or to take out private pension insurance.

Recent evidence suggests that an aging labor force can reduce the ability of firms to innovate as workers stay in their jobs longer [14]. This lack of job and worker reallocation has long-term negative effects on overall growth. Moreover, with older workers more likely 
to occupy high-skill jobs, delayed retirement may force young workers into occupational downgrading (taking a job below their skill level) or part-time work to find employment.

\section{LIMITATIONS AND GAPS}

There are several gaps in the literature that additional research will need to fill. First, the best evidence available is almost entirely for OECD countries. Although there is no theoretical reason to suspect that labor markets in developing countries show different patterns than those studied in the literature, a different degree of substitution between workers from different age cohorts might counteract the negative consequences of lowering the retirement age.

Second, there is only limited knowledge of how employment rates of young and older workers react during economic transitions. It may be that human capital acquired before a transitional phase is worth less than after transition, and that older workers acquire more of it than younger ones. Descriptions of the reallocation of employment during Eastern Europe's transitions from planned to market economies suggest that younger workers benefited from the transitions [15]. This development is probably the consequence of the depreciation of human capital that older workers acquired during the communist period that was in less demand during and after transition.

Third, the empirical evidence there is indicates a positive correlation between the employment rates of young and old workers. At the moment, however, there is no clear explanation for this relationship. This positive correlation could arise from firms' internal organization of their production process where young and old workers are complements. Alternatively, policies that focus on the employability of one group of workers may create positive spillover effects for other groups of workers, leading to an overall increase in employability. Here, more investigation is needed to offer a satisfactory explanation.

\section{SUMMARY AND POLICY ADVICE}

Early retirement amounts to higher labor costs and may dampen demand for young and old workers. OECD countries currently redesign their social security programs and pension schemes to create incentives for workers to raise effective retirement ages. Policymakers, however, need not fear that such pension reforms will create problems for younger workers since, in all likelihood, increasing labor demand for one cohort will lead to more overall employment.

Recent empirical evidence underscores a positive correlation between the employment of young and old workers, refuting the (popular) view that more jobs for older workers reduce the employment chances of younger workers. To the contrary: the weight of the empirical evidence indicates that increasing the employment of older workers leads to more jobs for younger workers.

\section{Acknowledgments}

The authors thank two anonymous referees and the IZA World of Labor editors for many helpful suggestions on earlier drafts. Version 2 of the article includes evidence from Japan, Italy, and Norway, and adds new "Key references" [9], [12], [13], [14]. 


\section{Competing interests}

The IZA World of Labor project is committed to the IZA Code of Conduct. The authors declare to have observed the principles outlined in the code.

(C) René Böheim and Thomas Nice 


\section{REFERENCES}

\section{Further reading}

Freeman, R. "Work-sharing to full employment: Serious option or populist fallacy?" In: Freeman, R., and P. Gottschalk (eds). Generating Jobs: How to Increase Demand for Less-Skilled Workers. New York: Russell Sage Foundation Press, 1998.

Scarpetta, S., A. Sonnet, and T. Manfredi. Rising Youth Unemployment During The Crisis: How to Prevent Negative Long-term Consequences on a Generation? OECD Social, Employment and Migration Working Paper No. 106, 2010.

\section{Key references}

[1] OECD. "Main economic indicators-Complete database." Main Economic Indicators (database).

[2] Schulze-Marmeling, S. France: EIRO CAR on "Helping Young Workers during the Crisis: Contributions by Social Partners and Public Authorities.” Brussels: Eurofound, 2011.

[3] Munnel, A., and A. Y. Wu. Will Delayed Retirement by the Baby Boomers Lead to Higher Unemployment among Younger Workers? Center for Retirement Research at Boston College Working Paper No. 2012-22, 2012.

[4] Fitzenberger, B., and K. Kohn. Skill Wage Premia, Employment, and Cohort Effects: Are Workers in Germany All of the Same Type? IZA Discussion Paper No. 2185, 2006.

[5] Schnalzenberger, M., and R. Winter-Ebmer. "Layoff tax and the employment of the elderly." Labour Economics 16:6 (2009): 618-624.

[6] Ahituv, A., and J. Zeira. "Technical progress and early retirement." Economic Journal 121:551 (2011): 171-193.

[7] Sapir, A. "Globalization and the reform of European social models." Journal of Common Market Studies 44:2 (2006): 369-390.

[8] Kalwij, A., A. Kapteyn, and K. de Vos. "Retirement of older workers and employment of the young." De Economist 158:4 (2010): 341-359.

[9] Kondo, A. "Effects of increased elderly employment on other workers' employment and elderly's earnings in Japan." IZA Journal of Labor Policy 5:2 (2016).

[10] Zhang, C. The Relationship between Elderly Employment and Youth Employment: Evidence from China. University Library of Munich MPRA Paper No. 37221, 2012.

[11] Gruber, J., and D. A. Wise (eds). Social Security Programs and Retirement around the World: The Relationship to Youth Employment. NBER Conference Report. Chicago: University of Chicago Press, 2010.

[12] Boeri, T., P. Garibaldi, and E. R. Moen. A Clash of Generations? Increase in Retirement Age and Labor Demand for Youth. CEPR Discussion Paper No. DP11422, 2016.

[13] Vestad, O. L. Early Retirement and Youth Employment in Norway. Oslo: Statistic Norway, 2013.

[14] Engbom, N. Firm and Worker Dynamics in an Aging Labor Market. Doctoral Thesis, 2017.

[15] Boeri, T., and K. Terrell. "Institutional determinants of labor reallocation in transition." Journal of Economic Perspectives 16:1 (2002): 51-76.

\section{Online extras}

The full reference list for this article is available from:

https://wol.iza.org/articles/effect-of-early-retirement-schemes-on-youth-employment View the evidence map for this article:

https://wol.iza.org/articles/effect-of-early-retirement-schemes-on-youth-employment/map 